\title{
Vertebral Artery Loops and Cervicobrachial Pain
}

\author{
Nichanametla Sravani ${ }^{1}$ Krishnan Nagarajan ${ }^{1} \quad$ Manchikanti Venkatesh ${ }^{1} \quad$ Veer S. Negi ${ }^{2} \quad$ Andi S. Ramesh ${ }^{3}$ \\ ${ }^{1}$ Department of Radio-Diagnosis, Jawaharlal Institute of Postgraduate \\ Medical Education \& Research, Pondicherry, India \\ 2Department of Clinical Immunology, Jawaharlal Institute of Postgraduate \\ Medical Education \& Research, Pondicherry, India \\ Address for correspondence Krishnan Nagarajan, MD, DM, \\ Department of Radio-Diagnosis, Jawaharlal Institute of Postgraduate \\ Medical Education \& Research, Pondicherry 605006, India \\ (e-mail: Iknagarajan1@gmail.com).
}

${ }^{3}$ Department of Neurosurgery, Jawaharlal Institute of Postgraduate

Medical Education \& Research, Pondicherry, India

Indian J Neurosurg:2020;9:193-196

\begin{abstract}
Keywords

- vertebral artery loops

- cervical radiculopathy

- magnetic resonance imaging

- CT angiography

Vertebral artery loop formation is an uncommon anatomical variation which may be asymptomatic or can cause cervicobrachial pain, radiculopathy, or even bone erosions and enlargement of neural foramina. As this entity is one of the uncommon causes of cervical radiculopathy, this report aims to create awareness among radiologists and clinicians, as vertebral artery loops may be seen incidentally in routine neuroimaging. magnetic resonance imaging (MRI) with magnetic resonance (MR) angiography or multislice computerized tomography (CT) angiography plays an important role in diagnosing as well as creating a roadmap for the surgery.

Vertebral artery loop formation as a cause of radiculopathy is an uncommon condition. An abnormal course of vessel can lead to vascular injury during surgery, hence preoperative evaluation with CT or MRI is essential. ${ }^{1,2}$ Anomalous looping of vertebral artery can cause neurovascular compression apart from bony erosion, widening of vertebral foramen, and even vertebrobasilar insufficiency. Clinical features of vertebral artery loop formation can be radiculopathy, compression over cervical cord leading to sensory and motor deficit, and vertigo when associated with vertebra-basilar insufficiency, which is known as vascular vertigo. It has also been postulated that loop formation of vertebral artery can also lead to posterior circulation infarcts. Left vertebral artery is more prone for loop formation than the right vertebral artery, probably due to increased caliber in greater proportion of individuals. Multilevel and bilateral tortuosity can occur in younger patients rarely where imaging plays an important role.
\end{abstract}

\section{Cases}

A 38-year-old female presented with complaints of neck pain and radiating pain to left upper limb. On examination, patient had mildly decreased power (four-fifths) of left upper limb with normal sensation. Patient was not a diabetic or hypertensive. Magnetic resonance imaging (MRI) of the cervical spine with magnetic resonance (MR) angiography of neck vessels was performed. Axial T2-weighted images showed anomalous left vertebral artery looping

DOI https://doi.org/

$10.1055 / \mathrm{s}-0040-1713057$

ISSN 2277-954X.
(V2 segment) entering the thecal sac and causing compression over cervical spinal cord along the left posterolateral aspect at C2 vertebral level. Another loop of left vertebral artery (V2 segment) was seen entering the left vertebral foramen at C3-4 intervertebral disc level, causing compression over exiting nerve root at this level ( - Fig. 1). MR angiography demonstrated the left vertebral artery entering the thecal sac and causing compression over cervical spinal cord at $\mathrm{C} 2$ vertebral level. The cervical cord showed no abnormal signal changes and right vertebral artery showed normal (c) 2020. Neurological Surgeons' Society of India.

This is an open access article published by Thieme under the terms of the Creative Commons Attribution-NonDerivative-NonCommercial-License, permitting copying and reproduction so long as the original work is given appropriate credit. Contents may not be used for commercial purposes, or adapted, remixed, transformed or built upon. (https://creativecommons.org/licenses/by-nc-nd/4.0/)

Thieme Medical and Scientific Publishers Pvt. Ltd., A-12, 2nd Floor, Sector 2, Noida-201301 UP, India 


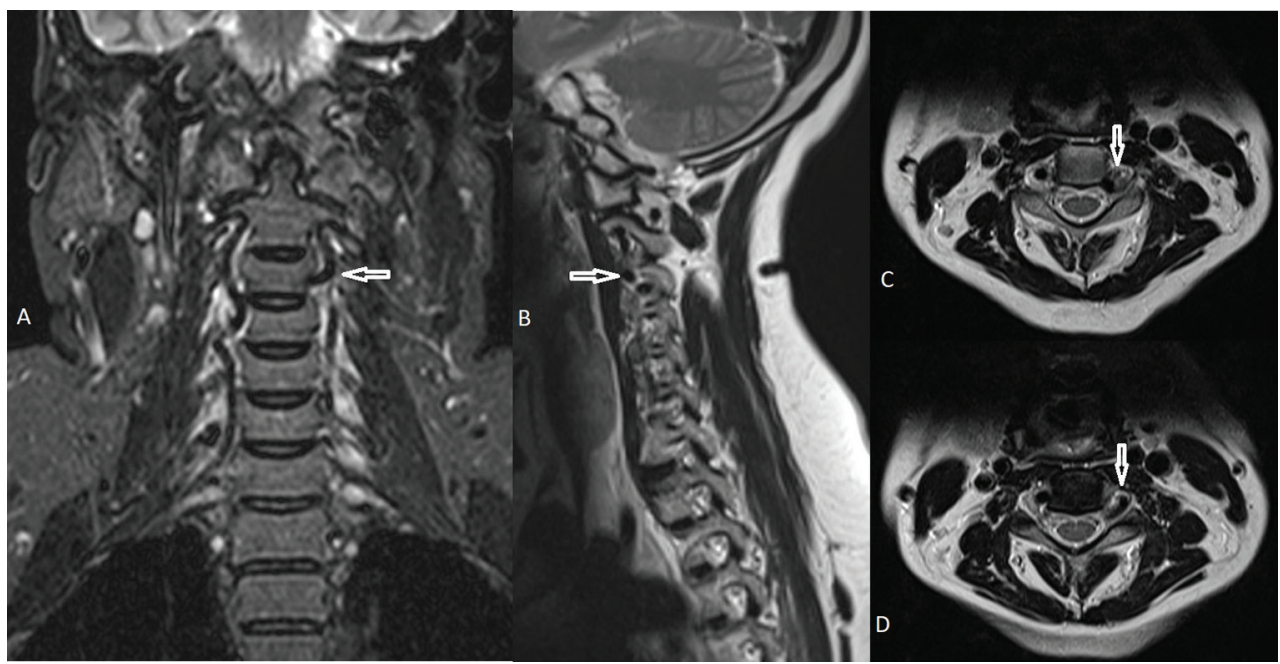

Fig. 1 Case 1. Coronal STIR (A) and T2 sagittal (B) sections of cervical spine showing the medial looping of left vertebral artery in left C3-4 neural foramen. The axial T2-weighted images (C and D) also showing the medial looping course of the left vertebral artery (arrows). Abbreviation: STIR, short T1 inversion recovery.

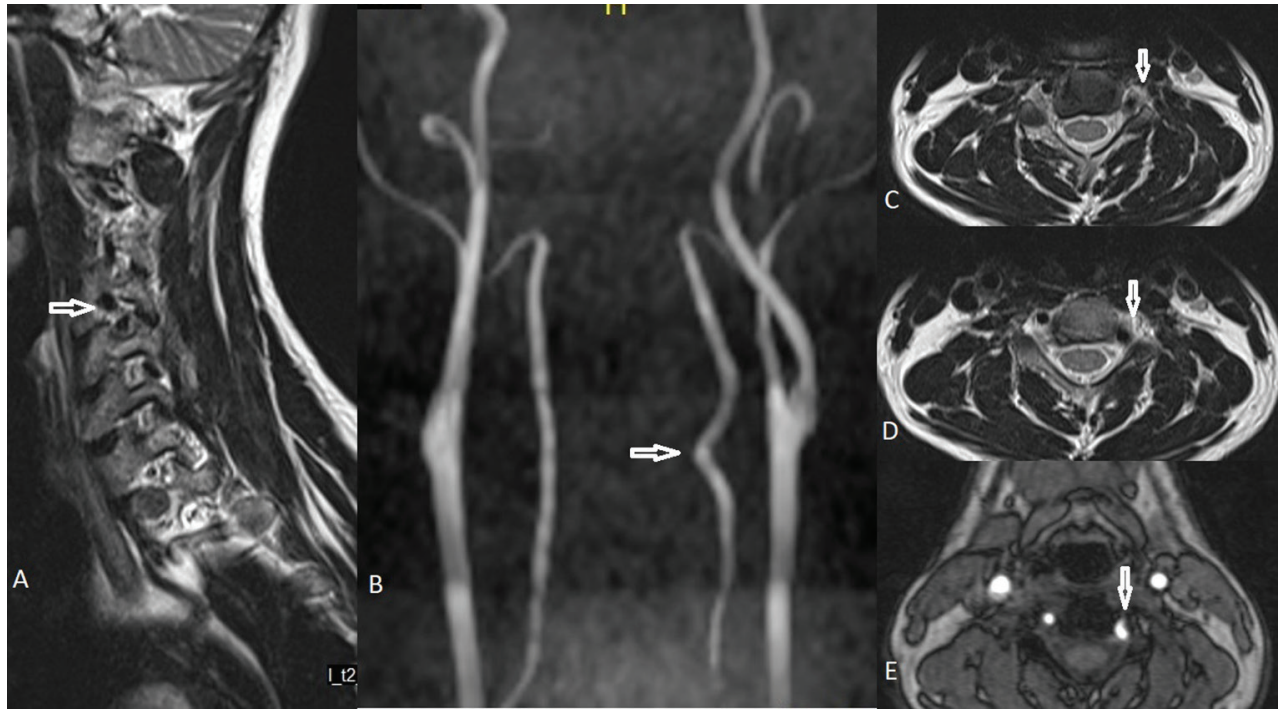

Fig. 2 Case 2. T2-weighted sagittal image (A) showing the hypointense flow-void of left vertebral artery in the left C4-5 neural foramen. MRA MIP coronal image (B), T2-weighted axial images ( $\mathbf{C}$ and $\mathbf{D}$ ) and MRA base image (E) showing the medial loop of left vertebral artery. Abbreviations: MIP, maximum intensity projection; MRA, magnetic resonance angiogram.

course. Another 39-year-old male presented with history of neck pain on-and-off for 6 months. No radicular pain or neurological deficit was noted. MRI of the cervical spine showed medial loop of left vertebral artery at C4-5 foraminal level ( - Fig. 2). Rest of the vertebral bodies, posterior elements, intervertebral discs, and thecal sac including the cord appeared normal. MR angiography of neck vessels clearly showed the medial loop in left vertebral artery in midcervical part corresponding to C4-5 level. As the patient was asymptomatic, this was considered as an incidental finding.

A 62-year-old female patient who was a known case of rheumatoid arthritis presented with recent onset of neck pain and occipital pain. Rheumatoid involvement of craniovertebral junction was suspected, and she underwent computerized tomography (CT) of the cervical spine and craniovertebral junction, as the patient had undergone right hip and bilateral knee arthroplasty 10 years back. CT showed erosions and joint space narrowing at the atlanto-axial articulation ( - Fig. 3). Along with that, there was a well-defined lytic area in the right posterolateral aspect of $C 4$ vertebral body with soft tissue density lesion within. CT angiography confirmed it to be the medial loop of right vertebral artery in the neural foramen, causing erosion of the vertebral body. The patient did not have any radicular symptoms in right shoulder or upper limb. The patient was conservatively managed due to comorbid rheumatoid disease. Her pain was relieved with analgesics and is on follow-up.

Theinitial reports suspected of having vertebral artery loops as a cause of cervical were based on diagnosis by $\mathrm{CT}$ imaging and digital subtraction angiography (DSA).-5 Further reports based on MRI were treated either by surgical microvascular decompression or managed conservatively. ${ }^{6,7}$ Paksoy et al ${ }^{8}$ in 


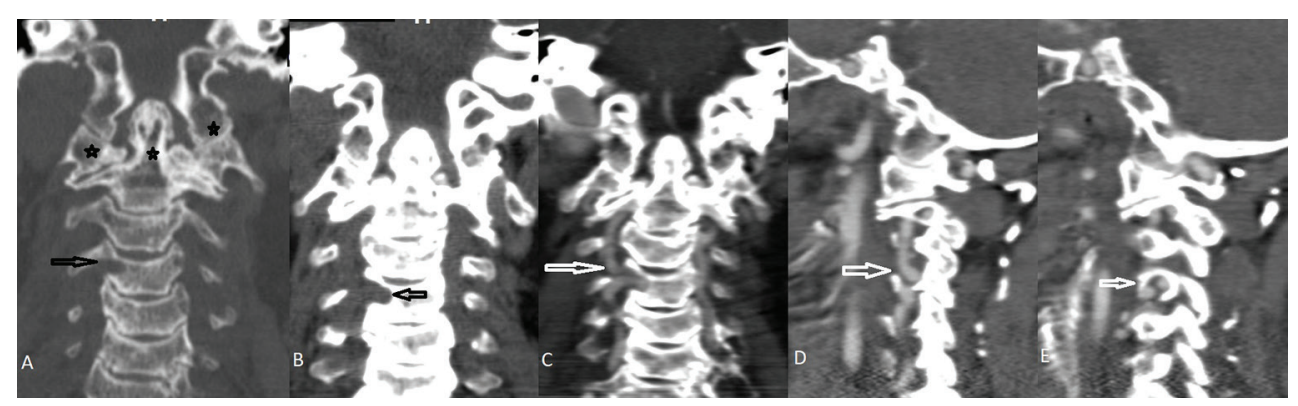

Fig. 3 Case 3. Coronal CT reformation showing the articular erosions and joint space narrowing (asterisks) involving the dens and atlanto-axial articulation due to rheumatoid arthritis. C4 vertebral body showed well-defined lytic area (arrows in $\mathbf{A}$ and $\mathbf{B}$ ) which on contrast reformations (coronal C, parasagittal $\mathbf{D}$ and $\mathbf{E}$ ) showed the right vertebral artery loop in the C4-5 neural foramen.

Table 1 Clinical and imaging findings in vertebral artery loops and cervicobrachial pain

\begin{tabular}{|l|l|l|l|}
\hline I. Asymptomatic & Bony changes & \\
\hline II. Symptomatic & $\begin{array}{c}\text { Local pain-neck } \\
\text { Occipital } \\
\text { Radicular-upper limb } \\
\text { Shoulder } \\
\text { Trigeminal (rarely) }\end{array}$ & Bony changes & $\begin{array}{l}\text { Intervertebral or transverse foraminal widening } \\
\text { Vertebral body erosions }\end{array}$ \\
\hline
\end{tabular}

their report on 137 patients with cervicobrachial pain, who underwent MRI with MR angiography over 7 months, found 13 patients to have vertebral artery loops. Of these, C6-7 was the commonest level of loop. None of them underwent surgery, and four patients with underlying hypertension were started on antihypertensive medication. Others were managed on analgesics and adjuvant antidepressants. Ganiyusufoglu et $\mathrm{al}^{9}$ reported the use of multidetector CT angiography as an equally useful modality to delineate the vertebral artery loop. Many reports mentioned the presence of intervertebral foraminal widening/enlargement or even obvious bony erosion due to the loop..$^{1,10}$ Park et al, ${ }^{2}$ in an evaluation of 1,000 MRIs of the cervical spine done over 3 years found six (0.6\%) patients (C3-4 and C4-5 three each) with medial loop and cervical root compression. They excluded cases of foraminal widening and erosion. Bruneau et $\mathrm{al}^{11}$ in their evaluation of 200 MR angiography and 50 CT angiography for variants of vertebral arteries found five patients (2.5\%) to have medial loop-three were at vertebral body level, causing widening of the transverse foramen, and two were at intervertebral disc level. Vertebral loops higher up at C2-3 level may present with cephalalgia or trigeminal symptoms and the possibility of this is to be kept, so that the cervical spine is included in the evaluation of headache. ${ }^{10,12,13}$

Based on the symptoms and presence of bony changes, the types of presentations that may be noted are shown in - Table 1.

Conservative management is initially followed, and surgery is indicated only if the patient develops severe neurological deficits. Few surgical options available are microvascular decompression and foraminotomy. Surgical approach is evolving, but the decision for the need for surgery in the absence of foraminal widening/erosion or intractable symptoms despite conservative medical therapy is to be considered on individual case basis and has not been yet established conclusively.,12,14,15 Most of the reported cases were treated conservatively, even though surgical decompression was attempted, if there was bony erosion or intractable neurological symptoms.

Identification of the vertebral artery loops is also important during the presurgical evaluation in any cervical spine surgery, particularly if implants like cages are planned. ${ }^{13}$ Prior identification of aberrant loop can avoid vascular injury during or after the placement of implants.

\section{Conflict of Interest}

None declared.

\section{References}

1 Kim HS, Lee JH, Cheh G, Lee S-H. Cervical radiculopathy caused by vertebral artery loop formation : a case report and review of the literature. J Korean Neurosurg Soc 2010;48(5):465-468

2 Park SB, Yang H-J, Lee SH. Medial loop of v2 segment of vertebral artery causing compression of proximal cervical root. J Korean Neurosurg Soc 2012;52(6):513-516

3 Pierron D, Lopez-Ibor L, Halimi P, Doyon D, Hurth M. [Vertebral artery loop and cervical pain]. J Radiol 1985;66(6-7):447-449

4 Wuttke V, Schmitt R, Pogan J, Clar HE. [Cervical nerve root compression syndrome caused by the vertebral artery]. RoFo Fortschr Geb Rontgenstr Nuklearmed 1990;152(4):473-474

5 Duthel R, Tudor C, Motuo-Fotso MJ, Brunon J. Cervical root compression by a loop of the vertebral artery: case report. Neurosurgery 1994;35(1):140-142

6 Yousry TA, Seelos K, Widenka DC, Steiger HJ. Vertebral artery loop causing cervical compression. Am J Neuroradiol 1996;17(9):1800-1801

7 Detwiler PW, Porter RW, Harrington TR, Sonntag VKH, Spetzler RF. Vascular decompression of a vertebral artery loop producing cervical radiculopathy. Case report. J Neurosurg 1998;89(3):485-488

8 Paksoy Y, Levendoglu FD, Ogün CO, Ustün ME, Ogün TC. Vertebral artery loop formation: a frequent cause of cervicobrachial pain. Spine 2003;28(11):1183-1188 
9 Ganiyusufoglu K, Kantarci M, Sirvanci M, Sildiroglu O, Alparslan L. Cervical radiculopathy caused by vertebral artery loop formation: multislice computed tomography angiography findings. J Comput Assist Tomogr 2005;29(1):133-135

10 Créac'h C, Duthel R, Barral F, et al. Positional cluster-like headache. A case report of a neurovascular compression between the third cervical root and the vertebral artery. Cephalalgia 2010;30(12):1509-1513

11 Bruneau M, Cornelius JF, Marneffe V, Triffaux M, George B. Anatomical variations of the V2 segment of the vertebral artery. Neurosurgery 2006;59, 1(Suppl 1):ONS20-ONS24, discussion ONS20-ONS24

12 Sellin JN, Al-Hafez B, Duckworth EA. Microvascular decompression of a C-2 segmental-type vertebral artery producing trigeminal hypesthesia. J Neurosurg 2014;121(4):919-923
13 Wakao N, Takeuchi M, Nishimura M, et al. Risks for vascular injury during anterior cervical spine surgery: prevalence of a medial loop of vertebral artery and internal carotid artery. Spine 2016;41(4):293-298

14 Hage ZA, Amin-Hanjani S, Wen D, Charbel FT. Surgical management of cervical radiculopathy caused by redundant vertebral artery loop. J Neurosurg Spine 2012;17(4):337-341

15 Gkekas N, Georgakoulias N. The medial loop of the V2 segment of the vertebral artery and the importance of this variation in correlation with the resection safe zone and technical characteristics of spinal cages during anterior cervical approaches. Acta Neurochir (Wien) 2013;155(7):1247-1248 